\title{
Lycopene treatment stalls the onset of experimentally induced hepatocellular carcinoma: a radioisotopic, physiological and biochemical analysis
}

\author{
Nisha Bhatia', Baljinder Singh ${ }^{2}$, Ashwani Koul' \\ 'Department of Biophysics, Panjab University, Chandigarh 160014, India. \\ ${ }^{2}$ Department of Nuclear Medicine, Post Graduate Institute of Medical Sciences and Research (PGIMER), Chandigarh 160012, India. \\ Correspondence to: Prof. Ashwani Koul, Department of Biophysics, Basic Medical Sciences (BMS) Block II, South Campus, Sec- \\ 25, Panjab University, Chandigarh 160014, India. E-mail: drashwanikoul@yahoo.co.in; ashwanik@pu.ac.in

\begin{abstract}
How to cite this article: Bhatia N, Singh B, Koul A. Lycopene treatment stalls the onset of experimentally induced hepatocellular carcinoma: a radioisotopic, physiological and biochemical analysis. Hepatoma Res 2018;4:9. http://dx.doi.org/10.20517/23945079.2018.04
\end{abstract}

Received: 24 Jan 2018 First Decision: 24 Feb 2018 Revised: 2 Mar 2018 Accepted: 19 Mar 2018 Published: 27 Mar 2018

Science Editor: Guang-Wen Cao Copy Editor: Jun-Yao Li Production Editor: Cai-Hong Wang

\begin{abstract}
Aim: The present study was aimed to determine the modulatory role of lycopene enriched tomato extract (LycT) during initiation of $\mathrm{N}$-nitrosodiethylamine (NDEA) induced hepatocellular carcinoma (HCC).

Methods: Female Balb/c mice were divided into 4 groups: control, NDEA (200 mg NDEA/kg b.wt, cumulative dose), LycT ( $5 \mathrm{mg} / \mathrm{kg}$ b.wt, thrice a week) and LycT + NDEA. LycT administration was commenced 2 weeks prior to NDEA administration in LycT + NDEA group.
\end{abstract}

Results: NDEA treatment caused histopathological alterations in hepatic tissue and was associated with enhanced serum levels of inflammatory markers, i.e., tumor necrosis factor-alpha, interleukin (IL)- 6 and IL- $\beta$. NDEA treatment also induced functional alterations in liver as evident by slow ${ }^{99 \mathrm{~m}} \mathrm{Tc}-$ mebrofenin hepatic excretion. LycT administration to NDEA mice showed improved hepatic functional status as demonstrated by normal ${ }^{99 \mathrm{~m}} \mathrm{Tc}-$ mebrofenin excretion. NDEA treatment also caused alterations in the hematological parameters such as hemoglobin, red blood cells, platelets and total leucocyte counts. A significant increase in plasma lipid peroxidation and decrease in reduced glutathione levels with alterations in various enzymatic antioxidants were observed upon NDEA treatment. LycT pre-treatment aided in boosting the antioxidant defense system and ameliorated the inflammatory and hematological alterations.

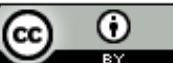

(C) The Author(s) 2018. Open Access This article is licensed under a Creative Commons Attribution 4.0 International License (https://creativecommons.org/licenses/by/4.0/), which permits unrestricted use, sharing, adaptation, distribution and reproduction in any medium or format, for any purpose, even commercially, as long as you give appropriate credit to the original author(s) and the source, provide a link to the Creative Commons license, and indicate if changes were made. 
Conclusion: As evident by improved functional, hematological and biochemical markers, it may be inferred that LycT has the potential to delay HCC initiation.

Keywords: Lycopene, ${ }^{99 \mathrm{mT}} \mathrm{Tc}-\mathrm{meb}$ rofenin, hepatocellular carcinoma, hematology, oxidative stress, inflammation

\section{INTRODUCTION}

Environmental factors including exposure to chemical pollutants due to growing industrialization and adoption of unhealthy lifestyle choices like physical inactivity, imbalanced dietary regimen and smoking play a major role in the etiology of various ailments including cancer. The existing structural embodiment of our environment and surroundings makes impossible to evade the exposure from its pernicious clutches. Among various pollutants, N-nitrosodiethylamine (NDEA) is a potent environmental carcinogen found in air, soil, water and food ${ }^{[1-3]}$. Metabolic activation of NDEA through hepatic biotransformation enzymes renders liver as a target organ for carcinogenesis. Hepatocellular carcinoma (HCC) is figured to be the fifth most common tumors of liver across the globe and accounts for $2.5 \%$ increase of death rates every year ${ }^{[4]}$. Extremely high incidence rate, poor prognosis and asymptomatic behavior associated with HCC makes its diagnosis restrictable at initial stages. Furthermore, angiogenesis and malignant nature of tumorous tissue may also reduce the life expectancy of HCC patients at later stages.

Early HCC diagnosis has become a priority in improving the survival among cancer patients. Despite the availability of various modalities for HCC treatment such as surgical resection, radiation and chemotherapy, the outcome of patient remains dismal. Additionally, various non-invasive modalities such as ultrasound, computed tomography, and magnetic resonance imaging are in use for early monitoring, diagnosis and stratification of $\mathrm{HCC}^{[5]}$. But these provide only anatomical information not the functional status of the tumorous tissue. Therefore, the development of non-invasive diagnostic techniques and identification of tumor specific serological markers linked to early stages of carcinogenesis would be of great clinical significance in the early management of HCC patients. This may be accomplished by ${ }^{99 m} \mathrm{Tc}-\mathrm{mebrofenin}$ hepatobiliary functional test that mainly relies on functional perturbations in the tissue as functional alterations precede anatomical alterations ${ }^{[6]}$. The main rationale behind the identification of candidate biomarkers relevant for cancer risk is to find a link between biological alterations in nonspecific tissues, such as blood, and the occurrence of similar events in specific tissues involved in the carcinogenesis. Moreover, blood acts as a pathological reflector of the systemic status of an animal exposed to carcinogen ${ }^{[7]}$.

Hematological parameters are surrogate markers playing a key role in diagnosing the extent of damage to blood thus acting as a prognostic indicator of HCC patient ${ }^{[8]}$. NDEA is also known to induce chronic inflammatory responses characterized by the upregulation of pro-inflammatory cytokines and recruitment of innate immune cells to liver tissue. Chronic inflammation further predisposes hepatic tissue to the development of $\mathrm{HCC}^{[9]}$. Free radicals and reactive oxygen species (ROS) generation during NDEA metabolism further causes the oxidation of major cellular biomolecules thus may augment an oxidative stress which may be postulated as a major contributor in the genesis of cancer ${ }^{[10]}$. Various reports support the relationship between the hepatic antioxidant system and development of hepatocarcinogenesis ${ }^{[1,12]}$. However, only few studies are available to evaluate the role of blood antioxidants in early diagnosis of $\mathrm{HCC}^{[13,14]}$. These observations emphasize the need for urgent implementation of efficient strategies to curb this disease. From the past few decades, preventive control approaches using the natural products derived from common dietary sources have been the main focus of scientific research to impede the induction of carcinogenesis ${ }^{[15]}$.

Lycopene extracted from red tomatoes has found its widespread use in natural medicine because of its highest antioxidant and radical scavenging activit ${ }^{[3,16-18]}$. Consumption of lycopene enriched tomato extract has been revealed to be effective in alleviating cancer progression due to its increased bioavailability and 
synergistic effects of its multiple phytochemicals ${ }^{[1,20]}$. The ameliorative potential of lycopene enriched extract has been found in patients of oesophageal cancer ${ }^{[21]}$. The consistently reduced risk of chronic diseases associated with increased consumption of lycopene enriched products provides a strong foundation for its use as a potent chemopreventive agent against liver cancer.

Our earlier studies have reported the delay in progression of hepatic cancer upon lycopene enriched tomato extract (LycT) consumption which was revealed by reduced histopathological alterations, improved survival rate, reduced tumor incidence and burden ${ }^{[3,18]}$. This was also evident through modulation in the expression of apoptosis and cell proliferation associated genes which further interferes in the progression of tumor cells ${ }^{[1,22]}$. We have also found that LycT consumption aided in up regulating the detoxification system, reducing chromosomal aberrations and modulating physiochemical characteristics of hepatocellular membrane ${ }^{[12]}$. Recently, in our laboratory, the role of LycT in inhibiting multiple dysregulated pathways including hypoxia, angiogenesis and metastasis has also been delineated. The study suggested that it does so by attenuating the expression of hypoxia inducible factor-alpha, vascular endothelial growth factor, cluster of differentiation 31, matrix metalloproteinases (MMP)-2 and MMP- ${ }^{[23]}$. Moreover, the modulation of hepatic tumor marker [alpha fetoprotein (AFP)] and hepatic functional markers by LycT was also demonstrated $^{[23]}$.

Thus the current scientific scenario has prompted us to study HCC during its early stages of development by analyzing a panel of hematological, inflammatory and blood antioxidant markers whose dysfunction may be related to critical events in hepatic cancer progression and their intervention with LycT. The assessment of these markers in blood on a regular basis along with AFP and liver function markers may allow earlier HCC detection. In addition, the physiological perturbations occurring in the hepatic tissue during carcinogenesis was also assessed using ${ }^{99 m}$ Tc-mebrofenin hepatobiliary functional test.

\section{METHODS}

\section{Animal model for development of HCC}

Female Balb/c mice (25-30 g) procured from the Central Animal House facility of Panjab University, Chandigarh (India) were provided standard animal pellet diet (Ashirwad Industries, Kharar, Punjab, India) and drinking water ad libitum. The animal house was maintained at a controlled temperature of $21{ }^{\circ} \mathrm{C} \pm 1{ }^{\circ} \mathrm{C}$ and humidity of $50 \%-60 \%$ with a 12 -h dark and light cycle. All the experimental studies were performed in accordance with the Indian National Science Academy Guidelines for the use and care of experimental animals and were initially approved by the Institutional Animal Ethics Committee (IAEC), Panjab University, Chandigarh (IAEC/284-295 at Sr. No. 47). The mice were acclimatized to the experimental conditions for duration of 1 week prior to the commencement of various treatments. LycT was extracted from red tomatoes using hexane/acetone/ethanol as an extraction medium as described by Gupta et al. ${ }^{[3]}$. The content of lycopene in the extract was estimated using UV-VIS spectrophotometer as described earlier ${ }^{[3]}$. LycT in the upper hexane layer showed the presence of three characteristic peaks, i.e., at 444, 470 and $503 \mathrm{~nm}$. Lycopene quantification was performed at $503 \mathrm{~nm}$ as to avoid the interferences from other carotenoids including $\beta$-carotene, lutein, neoxanthin, etc. ${ }^{[24,25]}$. The average lycopene content was approximately $14 \mathrm{mg} / \mathrm{kg}$ tomato $^{[3]}$.

Female Balb/c mice were randomly segregated into 4 groups. Animals of group 1 (control) were given vehicle (olive oil) treatment orally thrice a week. Animals of group 2 (NDEA) and group 4 (LycT + NDEA) received an intraperitoneal injection of NDEA at a cumulative dose rate of $200 \mathrm{mg} / \mathrm{kg}$ body weight for a total duration of 8 weeks. Group 3 (LycT) and group 4 animals were administered LycT in olive oil orally at a dose rate of $5 \mathrm{mg} / \mathrm{kg}$ body weight thrice a week for 10 weeks. Oral administration of LycT was commenced 2 weeks prior to NDEA treatment and continued until the termination of experimental period in LycT + NDEA group. 


\section{Assessment of hepatobiliary function}

At the end of 10th week, ${ }^{99 m}$ Tc-mebrofenin hepatobiliary functional test was performed to assess hepatocellular function, biliary obstruction and to quantify hepatic extraction fraction (HEF). 185-200 MBq of ${ }^{99 \mathrm{~m}} \mathrm{Tc}$ - sodium pertechnetate prepared in normal saline was mixed with mebrofenin according to the instructions provided by the manufacturer (BRIT, India). The scintillator counter was calibrated at $140 \mathrm{KeV}$ with a window setting of $\pm 20 \%$ using ${ }^{99 \mathrm{~m}} \mathrm{Tc}$ as a radioactive source. Mice were then positioned over the scintillation counter immediately after the intravenous administration of ${ }^{99 \mathrm{~m}} \mathrm{Tc}$-mebrofenin with liver and mediastinum in the field of view. Liver activity and blood pool activity was monitored as a function of time and then used to measure the percentage of activity retained by the hepatic tissue (hepatic retention). The time required for maximum uptake of mebrofenin $\left(\mathrm{T}_{\text {peak }}\right)$ as well as the time at which the activity reduces to its half $\left(\mathrm{T}_{1 / 2 \text { peak }}\right)$ was also calculated for the hepatic and cardiac tissues.

\section{Assessment of hematological parameters}

Collection of whole blood samples

Blood samples from mice of different groups were collected through an ocular vein in sterilized eppendorf containing anticoagulant at the end of treatment period. Blood samples were mixed properly and processed for the estimation of various hematological parameters.

\section{Hemoglobin}

The hemoglobin $(\mathrm{Hb})$ content was estimated in whole blood by cyanmethemoglobin method as given by Dacie and Lewis ${ }^{[26]}$. The estimation is based on the oxidation of hemoglobin to cyanmethemoglobin in presence of potassium ferricyanide. The intensity of red colored complex thus formed was measured spectrophotometrically at $540 \mathrm{~nm}$ against a Drabkin's solution and expressed as g/dL.

\section{Red blood cells}

Total red blood cell (RBC) counts were measured in non-coagulated whole blood as per the method described by Dacie and Lewis ${ }^{[26]}$. Hayem's fluid is an isotonic solution consisting of sodium sulphate, sodium chloride and mercuric chloride. The measurement is based on the dilution of blood samples with Hayem's fluid and then counting of the RBCs in four corners and one central square of a Neubauer's chamber. The RBC counts were further expressed as counts $\times 10^{6} / \mathrm{mm}^{3}$.

\section{Total leucocyte count}

The counting of total leucocytes (TLC) was performed in whole blood according to the method of Dacie and Lewis ${ }^{[26]}$ using Turk's fluid. The glacial acetic acid in this fluid causes the destruction of RBCs while the gentian violet helps in the staining of white blood cells (WBCs) nuclei makes them visible under the microscope. Counting of cells was done in four corner WBC squares and expressed as counts $\times 10^{3} / \mathrm{mm}^{3}$.

\section{Platelet count}

The counting of blood platelets was done in a hemocytometer using $1 \%$ ammonium oxalate as a platelet diluting fluid ${ }^{[26]}$. In this, oxalate induces the complete hemolysis of RBCs and preservation of platelets. The number of platelets were counted in whole blood in all the central RBC squares under a microscope and expressed as counts $\times 10^{5} / \mathrm{mm}^{3}$.

\section{Differential leucocyte count}

Differential leucocyte counting was performed to compute the presence and number of different type of leucocytes in blood according to the method of Dacie and Lewis ${ }^{[26]}$. The percentage (\%) counts of neutrophils and lymphocytes were determined by observing a blood smear under a microscope. 


\section{Assessment of inflammatory markers}

The quantitative estimation of various inflammatory markers including tumor necrosis factor (TNF)- $\alpha$, interleukin (IL)-1 $\beta$ and IL-6 was carried out in serum using a commercially available kit by solid phase enzyme linked immunosorbent assay according to the instruction provided by the manufacturer (RayBiotech, Inc., USA).

\section{Assessment of antioxidant defense system}

Preparation of blood plasma

At the end of various treatments, blood was withdrawn from the retro-orbital plexus of a mouse eye in an eppendorf containing EDTA as an anticoagulant. This was followed by the centrifugation of blood samples at $3000 \mathrm{rpm}$ for $15 \mathrm{~min}$ at $4{ }^{\circ} \mathrm{C}$. The supernatant (plasma) thus obtained was used for the estimation of various oxidative stress markers.

\section{Lipid peroxidation}

Lipid peroxidation (LPO) levels were measured in plasma as per the method described by Trush et al. ${ }^{[27]}$. It is based on the reaction of malondialdehyde (MDA) and thiobarbituric acid (TBA) to form pink colored MDATBA complex which has its maximum absorption intensity at $532 \mathrm{~nm}$. The amount of chromophore thus obtained was measured as an index of lipid peroxidation using an extinction coefficient of $1.56 \times 10^{5} \mathrm{M}^{-1} \mathrm{~cm}^{-1}$ and expressed as nanomoles of MDA-TBA chromophore formed/min/mg protein.

\section{Reduced glutathione}

The plasma levels of reduced glutathione (GSH) were estimated as a total non-protein sulphydryl compound according to the method of Moron et al. ${ }^{[28]}$. It involves the reduction of a 5,5'-dithiobis-2-nitrobenzoic acid by the -SH group of reduced GSH to produce a yellow colored 2-nitro-5-mercaptobenzoic acid. The optical density of the compound thus produced was measured spectrophotometrically at $412 \mathrm{~nm}$ and expressed as nanomoles of GSH/mg protein.

\section{Glutathione-S-transferase}

Plasma activity of glutathione-S-transferase (GST) was estimated using a method of Habig et al. ${ }^{[29]}$. GST aids in the coupling of GSH with a substrate, i.e., 1-chloro-2, 4 dinitrobenzene (CDNB). The absorbance of chromophore thus formed was read at $340 \mathrm{~nm}$ and described as micromoles of GSH-CDNB conjugates formed $/ \mathrm{min} / \mathrm{mg}$ protein using an extinction coefficient of $9.6 \mathrm{mM}^{-1} \mathrm{~cm}^{-1}$.

\section{GSH peroxidase}

Plasma GSH-peroxidase (Px) activity was assayed as per the method given by Paglia and Valentine ${ }^{[30]}$. It catalyzes the production of GSSG from GSH with the simultaneous oxidation of NADPH. The change in optical density was read at $340 \mathrm{~nm}$ based on an extinction coefficient of $6.22 \mathrm{mM}^{-1} \mathrm{~cm}^{-1}$ and expressed as nanomoles of NADPH consumed $/ \mathrm{min} / \mathrm{mg}$ protein.

\section{Glutathione reductase}

Plasma glutathione reductase (GR) activity was estimated according to the method of Williams and Arscott ${ }^{[31]}$. GR causes the reduction of GSSG to GSH using NADPH as a reducing agent with the simultaneous conversion of FAD to FADH: The change in optical density was monitored at $340 \mathrm{~nm}$ and calculated as nanomoles of NADPH consumed/min/mg protein using an extinction coefficient of $6.22 \mathrm{mM}^{-1} \mathrm{~cm}^{-1}$.

\section{Catalase}

Catalase (CAT) activity was determined in plasma using the method of Luck ${ }^{[32]}$. CAT assists in the breakdown of hydrogen peroxide to produce water and molecular oxygen. The activity was assayed at $240 \mathrm{~nm}$ and measured as international units (IU)/mg protein based on the extinction coefficient of $0.0394 \mathrm{mM}^{-1} \mathrm{~cm}^{-1}$. 


\section{Superoxide dismutase}

Plasma superoxide dismutase (SOD) activity was assayed according to the method of $\mathrm{Kono}^{[33]}$ based on the ability of SOD to inhibit the reduction of nitroblue tetrazolium (NBT) mediated by superoxide radicals, which were produced by photo-oxidation of hydroxylamine hydrochloride. One unit of SOD activity is the amount of enzyme required to cause $50 \%$ inhibition in optical density. The rate of reduction of NBT complex was measured at $560 \mathrm{~nm}$ and described as IU/mg protein.

\section{Assessment of histopathological alterations}

After the completion of the treatment period, mice were euthanized by decapitation and liver tissues were removed carefully followed by the immediate fixation of tissue in neutral formalin. Fixed liver tissue samples were embedded, sectioned and then stained using hematoxylin and eosin staining and examined for the microscopic alterations.

\section{Statistical analysis}

Data was expressed as mean \pm standard deviation (SD). Statistical significance was analyzed using one-way analysis of variance followed by least significant difference (LSD) post hoc test.

\section{RESULTS}

\section{Effect of LycT and/or NDEA on $99 \mathrm{mTc}$-mebrofenin hepatobiliary functional test}

After intravenous administration of ${ }^{99 m} \mathrm{Tc}-$ mebrofenin, NDEA induced a significant delay in the hepatocyte uptake, retention and excretion of ${ }^{99 m} \mathrm{Tc}-$ mebrofenin in comparison to control, LycT and LycT + NDEA mice [Figure 1A-D]. The hepatic extraction fraction at the end of $60 \mathrm{~min}$ of ${ }^{99 \mathrm{~m}} \mathrm{Tc}-\mathrm{mebrofenin}$ injection was observed to be around $8.9 \%, 61.9 \%, 11.5 \%$ and $17.8 \%$ in case of control, NDEA, LycT and LycT + NDEA group respectively [Figure $1 \mathrm{E}$ ]. Hepatic $\mathrm{T}_{\text {peak }}$ value was observed to be around $5 \mathrm{~min}$ in both control and LycT animals [Figure 2A]. However, NDEA administration led to a significant delay in attaining maximum activity thus showing a $\mathrm{T}_{\text {peak }}$ value of around 10 min while animals of LycT + NDEA group showed $\mathrm{T}_{\text {peak }}$ value of around $7 \mathrm{~min}$ [Figure $2 \mathrm{~A}$ ]. The hepatic $\mathrm{T}_{1 / 2 \text { peak }}$ value in case of control and LycT animals was observed to be around 7-8 min while it was around $22 \mathrm{~min}$ in case of LycT + NDEA group [Figure $2 \mathrm{~B}$ ]. In contrast, NDEA animals did not show any $\mathrm{T}_{1 / 2 \text { peak }}$ value which may be due to the extremely slow excretion rate of ${ }^{99}$ Tc-mebrofenin.

\section{Effect of LycT and/or NDEA on hematological parameters $\mathrm{Hb}$}

A significant decline in $\mathrm{Hb}$ levels was observed in mice of NDEA group when compared to control and LycT $(P \leq 0.001)$ groups [Table 1]. Likewise, animals of LycT + NDEA group showed a decrease in Hb levels in comparison to control and LycT $(P \leq 0.05)$ mice. However, a significant elevation in $\mathrm{Hb}$ levels was observed in mice that received LycT along with NDEA treatment when compared to NDEA $(P \leq 0.001)$ alone injected mice [Table 1]. No significant change in $\mathrm{Hb}$ levels was noticed between control mice and LycT administered mice.

\section{$R B C$}

NDEA administration caused a significant decrease in RBC counts in mice of NDEA group when compared to control and LycT $(P \leq 0.001)$ groups [Table 1]. Also, a decrease in RBC counts was observed in mice of LycT + NDEA group when compared to control and LycT $(P \leq 0.01)$ groups. But the increase in RBC counts was observed when NDEA mice were pre-treated with LycT when compared to NDEA $(P \leq 0.01)$ intoxicated mice [Table 1]. The counts of RBC did not differ significantly between mice of control and LycT groups.

\section{$T L C$}

TLCs were found to be enhanced in mice of NDEA group when compared to control and LycT $(P \leq 0.001)$ groups [Table 1]. In addition, mice of LycT + NDEA groups also showed elevated total leucocyte counts when 

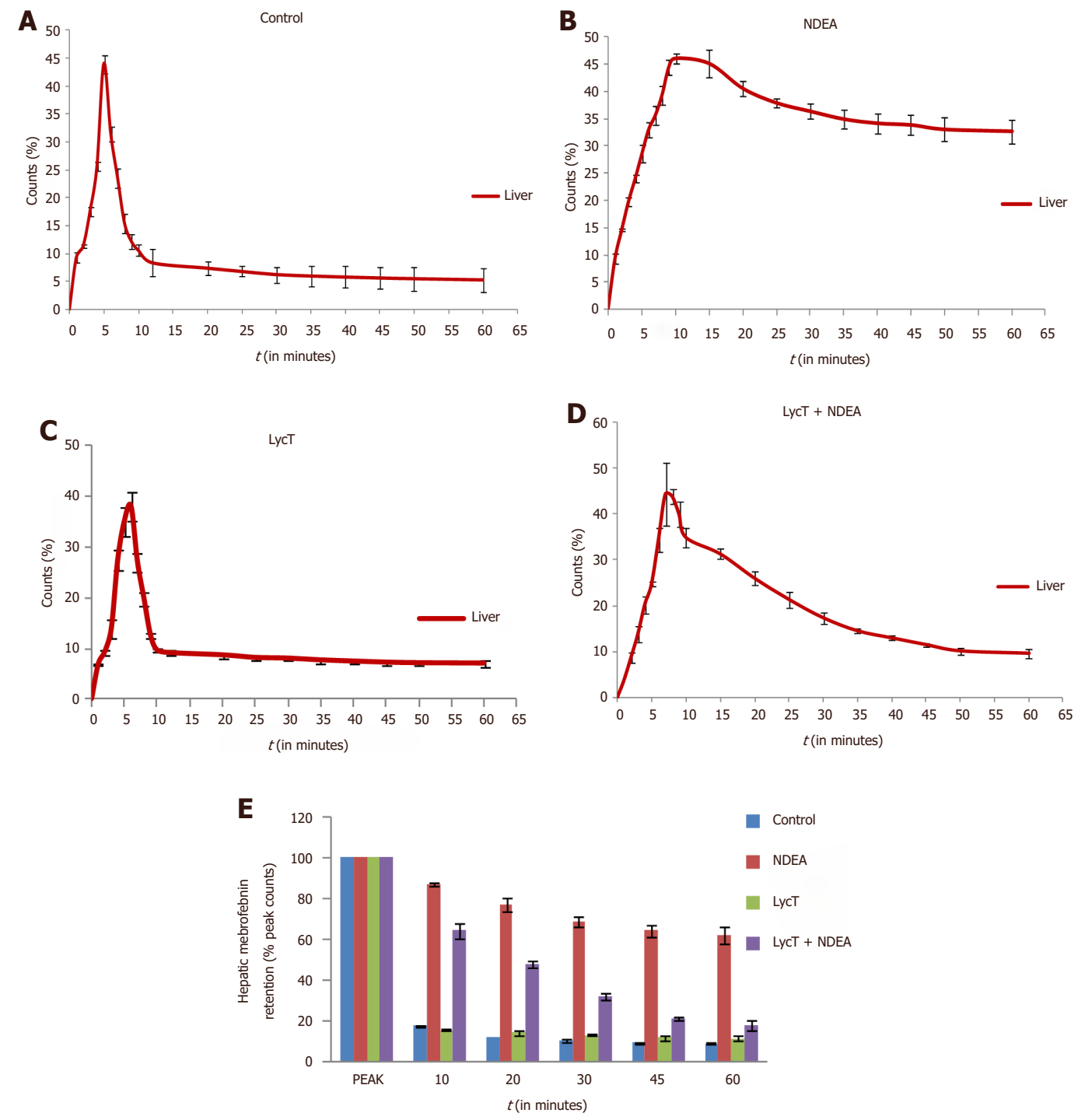

Figure 1. Effect of LycT and/or NDEA on liver time-activity curves and hepatic mebrofenin retention derived from ${ }^{99 \mathrm{~m}} \mathrm{Tc}$-labeled mebrofenin hepatobiliary functional test. Data is expressed as mean $\pm \mathrm{SD}(n=6)$. NDEA: N-nitrosodiethylamine; LycT: lycopene enriched tomato extract

compared to control and LycT $(P \leq 0.01)$ groups. However, the mice that received LycT in addition to NDEA treatment showed a reduction in TLC when compared to NDEA $(P \leq 0.01)$ mice [Table 1]. Moreover, no statistical difference in the blood TLC was found in LycT per se group and control group.

\section{Platelets}

The blood platelet counts were seen to be significantly decreased in NDEA mice as compared to control and LycT $(P \leq 0.001)$ mice [Table 1]. Likewise, a significant reduction in platelets counts was observed in LycT + NDEA group when compared to control $(P \leq 0.05)$ and LycT $(P \leq 0.01)$ group. In contrast, supplementation of NDEA mice with LycT induced a significant increase in platelet counts when compared to NDEA $(P \leq 0.001)$ mice. LycT pretreatment to mice did not induce any alterations in platelets counts in comparison to normal control mice.

\section{Neutrophils}

NDEA administration led to a significant enhancement in the neutrophil counts when compared to control and LycT $(P \leq 0.001)$ mice [Table 1]. Pretreatment of LycT to NDEA exposed mice also induced a marked 


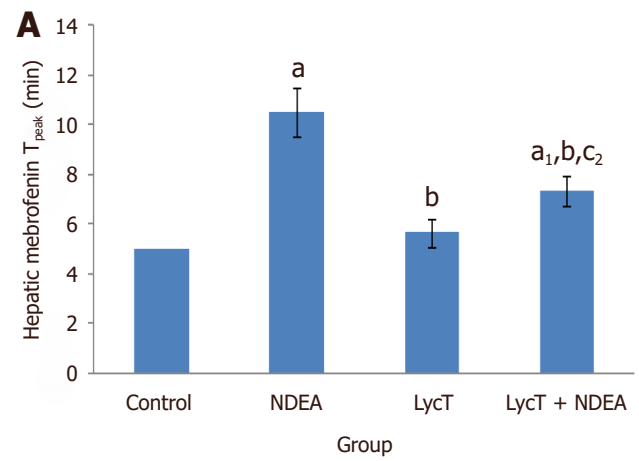

B

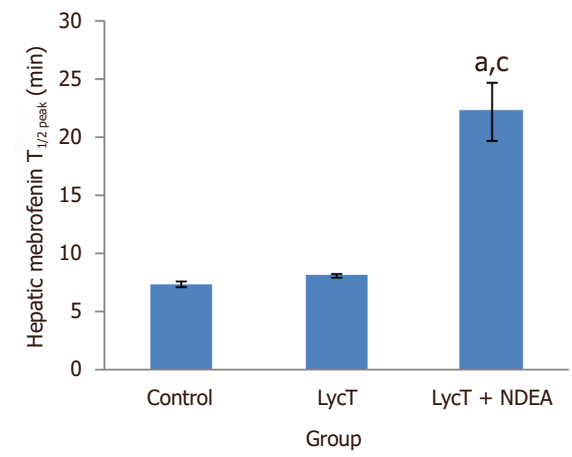

Figure 2. Effect of LycT and/or NDEA on hepatic $T_{\text {peak }}(A)$ and $T_{1 / 2 \text { peak }}(B)$ of ${ }^{99 m}$ Tc-labeled Mebrofenin in various treatment groups. Values are expressed as mean \pm SD $(n=5)$ and analyzed by one-way analysis of variance followed by $p o s t$ hoc test. ${ }^{a} P \leq 0.001$ and ${ }^{\text {al }} P \leq 0.01$, significant as compared to control group; ${ }^{b} p \leq 0.001$, significant as compared to NDEA group; ${ }^{\mathrm{c}} p \leq 0.001$ and ${ }^{\mathrm{c} 2} p \leq 0.05$, significant as compared to LycT group. NDEA: N-nitrosodiethylamine; LycT: lycopene enriched tomato extract

Table 1. Effect of LycT and/or NDEA on hematological parameters in different treated groups

\begin{tabular}{|c|c|c|c|c|}
\hline Hematological parameters & Control & NDEA & LycT & LycT + NDEA \\
\hline $\mathrm{Hb}(\mathrm{g} / \mathrm{dL})$ & $14.0 \pm 0.15$ & $10.6 \pm 0.42^{\mathrm{a}}$ & $14.1 \pm 0.21^{b}$ & $13.5 \pm 0.20^{\mathrm{a} 2, \mathrm{~b}, \mathrm{c} 2}$ \\
\hline RBC (counts $\times 10^{6} / \mathrm{mm}^{3}$ ) & $7.90 \pm 0.10$ & $6.53 \pm 0.35^{a}$ & $7.97 \pm 0.25^{b}$ & $7.17 \pm 0.15^{a 1, b 1, c 1}$ \\
\hline TLC (counts $\times 10^{3} / \mathrm{mm}^{3}$ ) & $7.53 \pm 0.29$ & $9.51 \pm 0.27^{\mathrm{a}}$ & $7.40 \pm 0.36^{b}$ & $8.45 \pm 0.30^{\mathrm{a} 1, \mathrm{~b}, \mathrm{cl}}$ \\
\hline Platelets (counts $\times 10^{5} / \mathrm{mm}^{3}$ ) & $4.43 \pm 0.29$ & $3.29 \pm 0.11^{a}$ & $4.69 \pm 0.18^{b}$ & $4.07 \pm 0.12^{a 2, b, c 1}$ \\
\hline Neutrophils (\%) & $29.7 \pm 1.53$ & $38.7 \pm 3.21^{a}$ & $27.3 \pm 2.52^{b}$ & $33.7 \pm 1.52^{\mathrm{b} 2, \mathrm{c} 1}$ \\
\hline Lymphocytes (\%) & $58.7 \pm 1.53$ & $49.7 \pm 2.08^{a}$ & $58.3 \pm 2.52^{b}$ & $55.7 \pm 2.51^{b 1}$ \\
\hline
\end{tabular}

Values are expressed as mean $\pm \mathrm{SD}(n=5)$ and analyzed by one-way analysis of variance followed by post hoc test. ${ }^{\mathrm{a}} P \leq 0.001,{ }^{\text {al }} P \leq 0.01$ and ${ }^{\mathrm{a} 2} p \leq 0.05$, significant as compared to control group; ${ }^{\mathrm{b}} p \leq 0.001,{ }^{\mathrm{b} 1} p \leq 0.01$ and ${ }^{\mathrm{b} 2} p \leq 0.05$, significant as compared to NDEA group; ${ }^{c 1} P \leq 0.01$ and ${ }^{c 2} P \leq 0.05$, significant as compared to LycT group. NDEA: N-nitrosodiethylamine; LycT: lycopene enriched tomato extract; $\mathrm{Hb}$ : hemoglobin; RBC: red blood cell; TLC: total leucocyte count

increase in neutrophil counts in comparison to LycT $(P \leq 0.01)$ mice and remained unaltered when compared to control mice. A significant decrease in these counts was observed in LycT + NDEA group when compared to NDEA $(P \leq 0.05)$ group. No statistical alterations in the neutrophil counts were observed in LycT per se group and control group.

\section{Lymphocytes}

NDEA treatment exhibited a marked decline in blood lymphocyte counts when compared to control and LycT $(P \leq 0.001)$ mice. However, no change in the lymphocyte counts was observed in LycT + NDEA group when compared to control and LycT groups [Table 1]. In contrast, LycT supplementation to NDEA exposed mice induced a significant enhancement in lymphocyte counts when compared to NDEA $(P \leq 0.01)$ intoxicated mice. No change was observed in the blood lymphocyte counts in LycT group when compared to control group.

\section{Effect of LycT and/or NDEA on serum inflammatory markers}

The levels of serum TNF- $\alpha$, IL-1 $\beta$ and IL- 6 were found to be elevated in mice exposed to NDEA when compared to control and LycT $(P \leq 0.001)$ mice. LycT supplementation to NDEA animals also induced a significant enhancement in the levels of TNF- $\alpha$ and IL-1 $\beta$ while IL- 6 levels remained unaltered as compared to control and LycT $(P \leq 0.001)$ mice [Figure $3 \mathrm{~A}-\mathrm{C}$ ]. On the contrary, animals of LycT + NDEA group revealed a marked reduction in the levels of these inflammatory cytokines in comparison to NDEA $(P \leq 0.001)$ afflicted group. No significant alterations in their levels were noticed between mice treated with LycT and control mice.

\section{Effect of LycT and/or NDEA on plasma enzymatic and non-enzymatic antioxidants $L P O$}

NDEA treatment significantly raised the plasma LPO levels when compared to control and LycT $(P \leq 0.001)$ mice [Table 2]. Further, a significant elevation in plasma LPO levels was also observed upon LycT 



Figure 3. Effect of LycT and/or NDEA on serum inflammatory markers in different treatment groups. Values are expressed as mean \pm SD $(n=5)$ and analyzed by one-way analysis of variance followed by post hoc test. ${ }^{\mathrm{a}} P \leq 0.001$, significant as compared to control group; ${ }^{\mathrm{b}} P \leq$ 0.001 , significant as compared to NDEA group; ${ }^{c} P \leq 0.001$, significant as compared to LycT group. NDEA: N-nitrosodiethylamine; LycT: lycopene enriched tomato extract; TNF: tumor necrosis factor; IL: interleukin

Table 2. Effect of LycT and/or NDEA on plasma antioxidant defense system in different treated groups

\begin{tabular}{|c|c|c|c|c|}
\hline & Control & NDEA & LycT & LycT + NDEA \\
\hline LPO (nmol of MDA-TBA chromophore formed/mg protein) & $0.02 \pm 0.002$ & $0.08 \pm 0.003^{\mathrm{a}}$ & $0.03 \pm 0.002^{b}$ & $0.05 \pm 0.005^{a, b, c}$ \\
\hline $\mathrm{GSH}$ (nmol of GSH/mg protein) & $7.60 \pm 0.23$ & $4.11 \pm 0.45^{\mathrm{a}}$ & $7.29 \pm 0.20^{b}$ & $6.25 \pm 0.59^{a, b, c}$ \\
\hline GR (nmol of NADPH oxidized/min/mg protein) & $1.06 \pm 0.08$ & $0.66 \pm 0.06^{\mathrm{a}}$ & $1.01 \pm 0.04^{b}$ & $0.88 \pm 0.04^{a, b, c]}$ \\
\hline GSH-Px (nmol of NADPH oxidized/min/mg protein) & $0.67 \pm 0.08$ & $1.06 \pm 0.09^{a}$ & $0.68 \pm 0.06^{b}$ & $0.81 \pm 0.05^{\mathrm{a}, \mathrm{b}, \mathrm{c} 1}$ \\
\hline GST ( $\mu \mathrm{mol}$ GSH-CDNB conjugates/min/mg protein) & $0.40 \pm 0.04$ & $0.55 \pm 0.02^{\mathrm{a}}$ & $0.38 \pm 0.04^{b}$ & $0.46 \pm 0.03^{a 1, b, c}$ \\
\hline SOD (IU/mg protein) & $0.10 \pm 0.008$ & $0.18 \pm 0.010^{a}$ & $0.11 \pm 0.007^{b}$ & $0.14 \pm 0.014^{a, b, c}$ \\
\hline CAT ( $\mu \mathrm{mol} / \mathrm{min} / \mathrm{mg}$ protein) & $0.61 \pm 0.01$ & $1.10 \pm 0.10^{\mathrm{a}}$ & $0.58 \pm 0.03^{b}$ & $0.84 \pm 0.02^{a, b, c}$ \\
\hline
\end{tabular}

Values are expressed as mean $\pm \mathrm{SD}(n=5)$ and analyzed by one-way analysis of variance followed by post hoc test. ${ }^{\text {a }} P \leq 0.001$ and ${ }^{\text {al }} P \leq$ 0.01 , significant as compared to control group; ${ }^{b} P \leq 0.001$, significant as compared to NDEA group; ${ }^{c} P \leq 0.001$ and ${ }^{c 1} p \leq 0.01$, significant as compared to LycT group. NDEA: N-nitrosodiethylamine; LycT: lycopene enriched tomato extract; LPO: lipid peroxidation; GSH: glutathione; GR: glutathione reductase; GSH-Px: GSH-peroxidase; GST: glutathione-S-transferase; SOD: superoxide dismutase; CAT: catalase; MDA-TBA: malondialdehyde-thiobarbituric acid; NADPH: nicotinamide adenine dinucleotide phosphate; CDNB: 1-chloro-2, 4 dinitrobenzene

supplementation to NDEA animals when compared to control and LycT $(P \leq 0.001)$ animals. However, the levels of LPO came down to the baseline levels in LycT + NDEA group in comparison to NDEA $(P \leq 0.001)$ group. No statistical difference in the plasma LPO levels was found in LycT per se group and control group.

\section{Reduced GSH}

The levels of plasma GSH were found to be declined in NDEA and LycT + NDEA mice as compared to control and LycT $(P \leq 0.001)$ mice [Table 2]. However, LycT pre-treatment to tumor bearing mice caused a significant enhancement in their levels when compared to NDEA $(P \leq 0.001)$ mice. No significant alterations were observed in plasma GSH levels of LycT per se group and control group. 


\section{GST}

NDEA administration induced a significant increase in plasma GST activity when compared to control and LycT $(P \leq 0.001)$ animals [Table 2]. Animals of LycT + NDEA group also showed a significant increase in GST activity in comparison to control $(P \leq 0.01)$ and LycT $(P \leq 0.001)$ animals. On the contrary, mice that received LycT in addition to NDEA showed a significant decrease in plasma GST activity as compared to NDEA ( $P \leq$ 0.001) alone administered group. No alterations were observed in plasma GST activity of LycT group when compared to control group.

\section{GSH-PX}

NDEA treated mice exhibited a significant increase in plasma GSH-Px activity when compared to control and LycT $(P \leq 0.001)$ mice [Table 2]. Likewise, plasma GSH-Px activity was raised in LycT + NDEA group when compared to control and LycT $(P \leq 0.01)$ group. However, administration of LycT to NDEA group of animals induced a significant reduction in the GSH-Px activity when compared to NDEA $(P \leq 0.001)$ treated mice. Plasma GSH-Px activity did not differ significantly between the control and LycT group of animals.

\section{$G R$}

NDEA exposure exhibited a significant decline in plasma GR activity in comparison with control and LycT $(P \leq 0.001)$ animals [Table 2]. Similarly, a significant decrease in GR activity was also observed in LycT + NDEA group when compared to control $(P \leq 0.001)$ and LycT $(P \leq 0.01)$ group. In contrast, there was a marked increase in GR activity on LycT supplementation to NDEA afflicted animals when compared to NDEA $(P \leq 0.001)$ alone group. No significant alteration in the plasma activity of GR was observed between the control and LycT group.

\section{CAT}

A significant increase in plasma CAT activity was observed in NDEA and LycT + NDEA group of animals when compared to control and LycT $(P \leq 0.001)$ mice [Table 2]. In contrast, pretreatment of NDEA exposed animals with LycT induced a significant decrease in CAT activity when compared to NDEA $(P \leq 0.001)$ animals. Plasma CAT activity remained unaltered in mice treated with LycT as compared to control mice.

\section{SOD}

The administration of NDEA caused a significant increase in plasma SOD activity in animals of both NDEA and LycT + NDEA group when compared to control and LycT $(P \leq 0.001)$ mice [Table 2]. On the contrary, a significant decrease in SOD activity was observed in LycT + NDEA group when compared to NDEA $(P \leq 0.001)$ afflicted group. There was no significant alteration in SOD activity between mice treated with LycT and normal control mice.

\section{Effect of LycT and/or NDEA on histopathological alterations}

Liver sections from control and LycT mice exhibited normal histoarchitecture [Figure 4A and C]. Hexagonal hepatic lobules containing central vein in the middle and portal triad at the periphery were visible. Liver acinus was divided into three zones: zone 1, zone 2 and zone 3. Liver sections from NDEA group showed the presence of high grade dysplasia characterized by architectural and nuclear atypia, differential cytoplasmic staining with diminished sinusoidal spaces and fatty accumulation. No stromal invasion was visible in mice of NDEA group. Liver sections obtained from animals of LycT + NDEA group exhibited mild hepatocellular damage with no vascular invasion [Figure $4 \mathrm{~B}$ and D; Table 3].

\section{DISCUSSION}

Increased oxidative stress and altered redox status during carcinogenesis accentuate the need for developing efficient strategies in curtailing the cancer development. This may be accomplished via use of LycT as an 

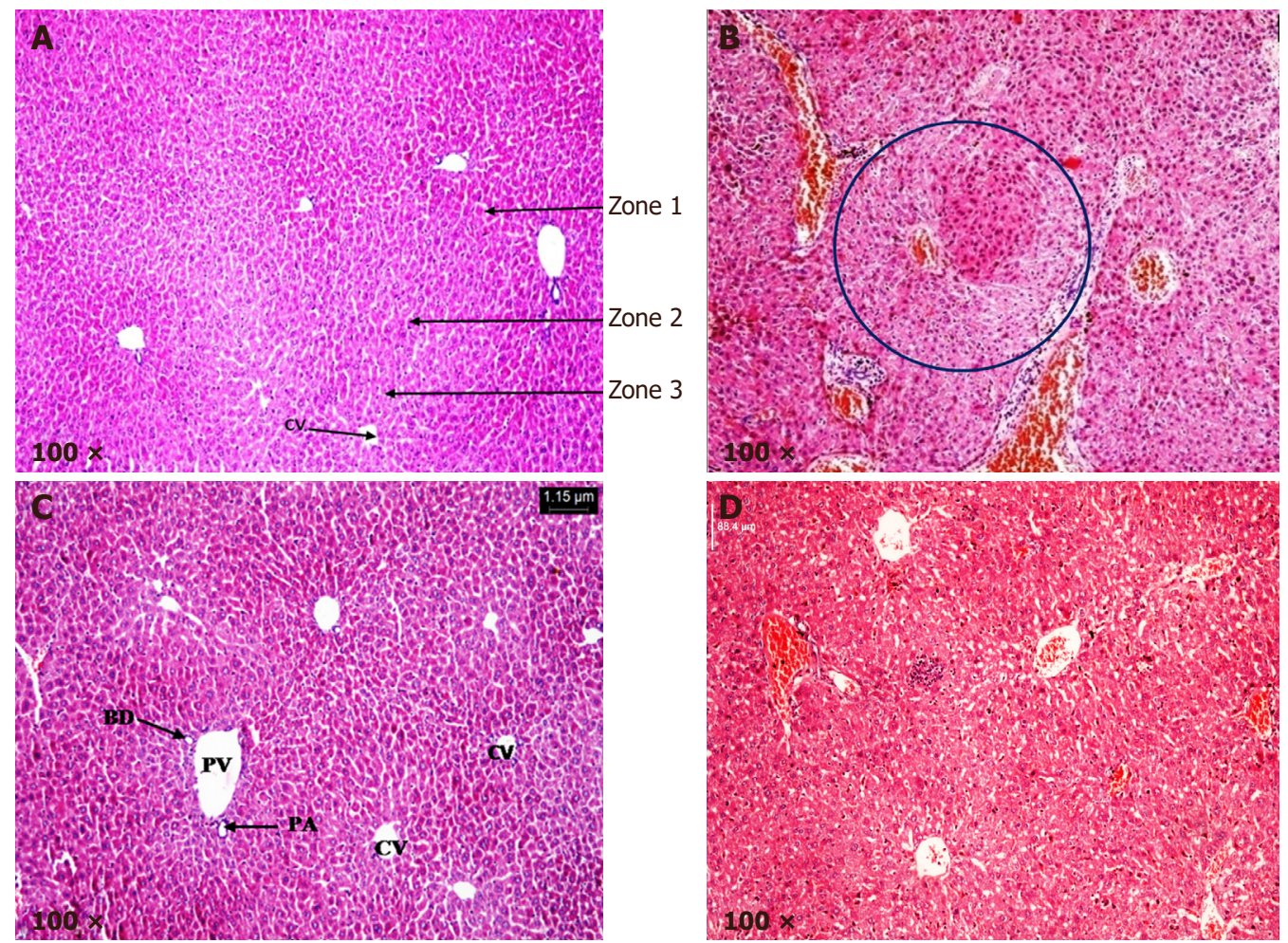

Figure 4. Histopathological analysis of hepatic tissue in various treated groups. (A) Liver sections from control group at 100× magnification revealing normal histo-architecture and the presence of three zones: zone 1, zone 2 and zone 3; (B) liver sections from NDEA group at 100× magnification revealing high grade dysplasia (encircled); (C) liver sections from LycT group at 100× magnification revealing normal histo-architecture; (D) liver sections from LycT + NDEA group at 100× magnification revealing near normal histoarchitecture with infiltration of lymphocytes. CV: central vein; PA: hepatic portal artery; PV: hepatic portal vein; BD: bile duct

Table 3. Histopathological quantification of hepatic damage in NDEA and LycT + NDEA group

\begin{tabular}{lcc}
\hline Groups/parameters & NDEA & LycT + NDEA \\
\cline { 2 - 3 } Cell density & ++ & + \\
Architectural atypia & ++ & + \\
Nuclear density & ++ & + \\
Differential cytoplasmic staining & ++ & - \\
Fatty accumulation & ++ & - \\
\hline
\end{tabular}

+++: extensively observed; ++: moderately observed; +: mildly observed; -: not observed. NDEA: N-nitrosodiethylamine;

LycT: lycopene enriched tomato extract

exogenous antioxidant to maintain the redox balance and homeostasis. The role of LycT in delaying the process of hepatocarcinogenesis has already been studied in terms of diminished histopathological alterations, reduced mortality and induction of apoptosis ${ }^{[3,18]}$. Moreover, the anti-angiogenic and anti-metastatic potential of lycopene was also investigated recently in our laboratory ${ }^{[23]}$. Periodical assessment of serological markers at early stages could serve as an important parameter to evaluate the onset of hepatic pathology. Thus the present piece of work was planned to gain insight into the identification of candidate biomarkers linked to early stages of hepatocarcinogenesis and their amelioration by LycT. In addition, the physiological status of the liver was also assessed using non-invasive ${ }^{99 \mathrm{~m}} \mathrm{Tc}-\mathrm{mebrofenin}$ hepatobiliary functional test.

It helps in the evaluation of hepatocellular function, biliary obstruction thus providing the functional or physiological status of liver. In the present study, an appearance of maximum activity of ${ }^{99 m}$ Tc-mebrofenin in blood pool within 2-3 min in all the groups showed that NDEA exposure does not induce any effect on cardiac tissue. Being a hepatocarcinogen, NDEA induces major pathophysiological alterations in the 
hepatic tissue as observed by the changes in HEF, percentage counts in the liver at different time intervals, $\mathrm{T}_{\text {peak }}$ and $\mathrm{T}_{1 / 2 \text { peak }}$. Control and LycT animals showed the normal uptake, efficient hepatic extraction and rapid excretion from the liver. However, a significant deviation from the normal pattern of radioactivity as observed in NDEA animals confirmed the physiological alterations in hepatic tissue. The delay in hepatic uptake in NDEA animals may be due to severe hepatocellular dysfunction. Neyt et al. ${ }^{[34]}$ have also reported the delayed uptake due to the dysfunction of various Oatp transporters located on hepatocytes. The retention of radiotracer activity in the liver of NDEA mice up to 60 min showed marked impairment in the excretion of the activity. This may be due to the biliary obstruction induced by NDEA which was also evidenced by the inability to calculate $\mathrm{T}_{1 / 2}$ value in case of NDEA animals. We have previously reported the delay in hepatic excretion in the case of DMBA induced hepatotoxicity ${ }^{[35]}$. Joseph et al. ${ }^{[36]}$ observed the involvement of inflammation in delaying the hepatic excretion of ${ }^{99 m}$ Tc-mebrofenin. Similarly, LycT administration to NDEA insulted animals also showed delayed uptake but the clearance of the activity at 60 min showed the protective effect of LycT against hepatocarcinogenesis. Deshpande et al.$^{[37]}$ observed the increased clearance of ${ }^{99 m} \mathrm{Tc}-$ mebrofenin upon administration of dietary turmeric extract to rats exposed to D-galactosamine $\mathrm{HCl}$. Our laboratory also observed the ameliorative effect of Azadirachta indica against DMBA induced hepatotoxicity by efficient clearance of mebrofenin ${ }^{[35]}$.

During tumor progression, cells generally demand more oxygen than is available for its growth, which results in the creation of hypoxia. Continued hypoxia leads to the adaptation of various genomic and proteomic alterations and results in the aggressive and malignant tumor phenotype. This may further causes reduced oxygen transport throughout the body due to the alterations in various hematological markers. NDEA exposed mice showed a marked decline in the levels of $\mathrm{Hb}, \mathrm{RBC}$, platelets and lymphocytes as compared to control mice. In addition to this, a significant enhancement in the neutrophils and WBC counts were observed upon NDEA exposure. The reduction in $\mathrm{Hb}$ and $\mathrm{RBC}$ suggested the occurrence of anemia in tumor bearing mice. This may be due to the increased oxidative stress induced by excessive ROS which causes the oxidative destruction of mature erythrocytes or inhibiting its production. This can also be evidenced by a decline in GSH and elevation in LPO levels on NDEA treatment ${ }^{[38]}$. A marked enhancement in WBC counts may reflect the activation of an immune system to fight against invading particles ${ }^{[39]}$. This was further confirmed by the release of various cytokines by activated kupffer cells and accumulation of neutrophils in hepatic cells as discussed above. Histopathological examination also supported the infiltration of leukocytes in hepatic tissue upon NDEA administration. The diminished platelets count may apparently be due to the decreased production of thrombopoietin hormone by damaged liver cells. The decrease in lymphocytes and enhanced neutrophil counts might suggest the decrease in efficiency of an immune system to cope up with the triggered inflammatory cascade ${ }^{[40]}$. Similar observations were also noticed by Farooq et al..$^{[4]]}$ and Gangar et al. ${ }^{[42]}$, who also observed the alterations in various hematological parameters in patients suffering from gastric and forestomach carcinoma respectively. LycT treatment to NDEA insulted mice tends to restore the levels of these markers which might be attributed to decreased hypoxia and reduction in tumor growth by an enhancement of apoptosis ${ }^{[18,23]}$. Several other researchers have also supported the restoration of blood parameters upon lycopene treatment thus showing its anti-inflammatory potential ${ }^{[43,44]}$.

Inflammatory cytokines also play a major role in the progression of cancer. Exposure of liver tissue to certain hepatotoxicants induces the release of pro-inflammatory cytokines by kupffer cells which can further aggravate the tumor progression by triggering of inflammatory cascade ${ }^{[45]}$. The current findings revealed a marked increase in serum levels of various inflammatory markers, i.e., TNF- $\alpha$, IL-1 $\beta$ and IL-6 in tumor bearing mice. Overexpression of these cytokines may provide proliferating signals to the mutated hepatocytes through the secretion of angiogenesis and metastasis markers. These findings were in concordance with the report of Abdel-Hamid et al. ${ }^{[46]}$. Supplementation of NDEA mice with LycT modulated the serum levels of these cytokines by inhibiting their production and induction of apoptosis thus showing its anti-inflammatory effect. Literature also supported the amelioration of these inflammatory markers upon administration of lycopene ${ }^{[47-49]}$. 
NDEA treatment also exhibited enhanced plasma LPO and reduced GSH levels in comparison to control and LycT animals. The increase in LPO may be ascribed to the excessive formation of ROS and their diffusion into the blood by an oxidative deterioration of membrane lipids. Declined GSH levels might be due to the impairment of antioxidant defense system and increased consumption of GSH by the detoxification system. Literature also supported the alterations in these oxidative stress markers with the progression of cancer ${ }^{[0,51]}$. Interestingly, the reversal of their levels by LycT pretreatment may probably be due to the neutralization of free radicals and enhancement of xenobiotic detoxification by LycT. The amelioration of oxidative stress by consumption of tomato enriched diet has also been reported by Dogukan et al ${ }^{[52]}$ and Gupta et al ${ }^{[12]}$.

The enhancement in plasma activities of SOD, CAT and GSH-Px were also observed upon NDEA administration. An elevated SOD activity causes the excessive production of deleterious $\mathrm{H}_{2} \mathrm{O}_{2}$ by the dismutation of superoxide anions which may further be counterbalanced by excess CAT and GSH-Px. However, complete neutralization of $\mathrm{H}_{2} \mathrm{O}_{2}$ may not occur due to the failure of defense system by sufficient lipid oxidation which further increases the chances of DNA damage, thus, contributing to a growth advantage to the tumorous cell ${ }^{[53]}$. Our results are in agreement with other reports who found similar alterations in activities of these enzymes in cancer patients ${ }^{[4,55]}$. Reduction in the activities of these enzymes by LycT supplementation to tumor bearing mice showing the antioxidant capability of LycT to scavenge the free radical formation thus mitigating intracellular oxidative damage. The present results are in harmony with the findings of Ural ${ }^{[56]}$ and Ibrahim $^{[44]}$ who also reported the diminished enzymatic activities on LycT supplementation.

The increase in GST activity in NDEA intoxicated mice may lead to the excessive utilization of this enzyme in the detoxification in response to metabolic induction in the tumor cells. These results are in concordance with the observation of Sadik et al. ${ }^{[57]}$, who also reported the correlation between the increased GST levels and carcinogenesis. In contrast, Li et al. ${ }^{[58]}$ has observed the decrease in blood GST levels during the development of HCC. Suppression of GST activity upon LycT supplementation to NDEA afflicted mice indicated the protective efficacy of LycT against the induction of oxidative stress. Sadik et al. ${ }^{[57]}$ has also reported the restoration of GST activity upon consumption of a diet rich in fruits and vegetables. The increased activity of GSH-Px and decreased levels of GSH may lead to the accumulation of oxidized glutathione (GSSG) which further cannot be converted to GSH due to the reduction in GR activity upon NDEA treatment. Maffei et al. ${ }^{[55]}$ has also reported the drop in plasma GR activity in patients suffering from colorectal cancer. Pretreatment with LycT to NDEA mice attenuated the decrease in GR activity probably by radical scavenging potential and increase in GSH level thus maintaining the oxido-reductive balance. Lycopene enriched tomato extract ameliorates the oxidative stress by maintaining the integrity of cellular membrane thus preserving the antioxidants levels in the liver cells ${ }^{[12,59]}$. The activities of various enzymatic and non-enzymatic antioxidants did not show any alterations between control and LycT mice.

It is evident that LycT supplementation modulated the inflammatory and hematological markers, boosted the antioxidant system and improved the functional status of hepatic tissue in tumor bearing mice. Data from the present study and previously published studies reiterate the potential of LycT in delaying the initiation of HCC which may have significant implications in its overall chemopreventive potential.

\section{DECLARATIONS}

\section{Authors' contributions}

Study design: Koul A, Singh B

Data analysis and manuscript preparation: Koul A, Singh B, Bhatia N

Experimental studies: Bhatia $\mathrm{N}$

Literature search: Koul A, Singh B, Bhatia N

Manuscript review: Koul A, Singh B, Bhatia N 


\section{Data source and availability}

The data presented is original and obtained in our laboratory. It is available with the authors and can be made available if required.

\section{Financial support and sponsorship}

This work was supported by the Department of Science and Technology (Innovation in Science Pursuit for Inspired Research-INSPIRE Program) (IF110576).

\section{Conflicts of interest}

The authors declare that they have no conflicts of interest.

\section{Patient consent}

Not applicable.

\section{Ethics approval}

All the experimental studies were performed in accordance with the Indian National Science Academy Guidelines for the use and care of experimental animals and were initially approved by the Institutional Animal Ethics Committee (IAEC), Panjab University, Chandigarh (IAEC/284-295 at Sr. No. 47).

\section{Copyright}

(c) The Author(s) 2018.

\section{REFERENCES}

1. Bharati S, Rishi P, Koul A. Azadirachta indica exhibits chemopreventive action against hepatic cancer: studies on associated histopathological and ultrastructural changes. Microsc Res Tech 2012;75:586-95.

2. Glory MD, Thiruvengadam D. Potential chemopreventive role of chrysin against N-nitrosodiethylamine-induced hepatocellular carcinoma in rats. Biomed Prev Nutr 2012;2:106-12.

3. Gupta P, Bansal MP, Koul A. Spectroscopic characterization of lycopene extract from Lycopersicum esculentum (Tomato) and its evaluation as a chemopreventive agent against experimental hepatocarcinogenesis in mice. Phytother Res 2013;27:448-56.

4. Seigel RL, Miller KD, Jemal A. Cancer statistics. CA Cancer J Clin 2015;65:5-29.

5. Chou R, Cuevas C, Fu R, Devine B, Wasson N, Ginsburg A, Zakher B, Pappas M, Graham E, Sullivan SD. Imaging techniques for the diagnosis of hepatocellular carcinoma: a systematic review and meta-analysis. Ann Intern Med 2015;162:697-711.

6. Geisel D, Lüdemann L, Hamm B, Denecke T. Imaging-based liver function tests--past, present and future. Rofo 2015;187:863-71.

7. Olafadehan OA. Haematological parameters, serum constituents and organ development of growing rabbits as affected by feeding of processed cassava peels. Anim Nutr Feed Technol 2011;11:41-51.

8. Gebo KA, Chander G, Jenckes MW, Ghanem KG, Herlong HF, Torbenson MS, El-Kamary SS, Bass EB. Screening tests for hepatocellular carcinoma in patients with chronic hepatitis C: a systematic review. Hepatology 2002;36:S84-92.

9. Capece D, Fischietti M, Verzella D, Gaggiano A, Cicciarelli G, Tessitore A, Zazzeroni F, Alesse E. The inflammatory microenvironment in hepatocellular carcinoma: a pivotal role for tumor-associated macrophages. Biomed Res 2013;2013:187204.

10. Hess JA, Khasawneh MK. Cancer metabolism and oxidative stress: insights into carcinogenesis and chemotherapy via the nondihydrofolate reductase effects of methotrexate. BBA Clin 2015;3:152-61.

11. Lin CC, Yin MC. B vitamins deficiency and decreased anti-oxidative state in patients with liver cancer. Eur J Nutr 2007;46:293-9.

12. Gupta P, Bansal MP, Koul A. Lycopene modulates initiation of N-nitrosodiethylamine induced hepatocarcinogenesis: studies on chromosomal abnormalities, membrane fluidity and antioxidant defense system. Chem Biol Interact 2013;206:364-74.

13. Arslan A, Demir H, Ozbay MF, Arslan H. Evaluation of lipid peroxidation and some antioxidant activities in patients with primary and metastatic liver cancer. $J$ Cancer Ther 2014;5:192-7.

14. Shaban NZ, Salem HH, Elsadany MA, Ali BA, Hassona EM, Mogahed FAK. Alterations in lipid peroxidation and antioxidants in patients' with different stages of hepatitis B virus infection in Egypt. Life Sci J 2014;11:960-7.

15. Koul A, Bharrhan S, Singh B, Rishi P. Potential of Azadirachta indica against Salmonella typhimurium-induced inflammation in BALB/ c mice. Inflammopharmacology 2009;17:29-36.

16. Palozza P, Parrone N, Catalano A, Simone R. Tomato lycopene and inflammatory cascade: basic interactions and clinical implications. Curr Med Chem 2010;17:2547-63.

17. Sahin M, Sahin E, Gümüşlü S. Effects of lycopene and apigenin on human umbilical vein endothelial cells in vitro under angiogenic stimulation. Acta Histochem 2012;114:94-100. 
18. Gupta P, Bansal MP, Koul A. Evaluating the effect of lycopene from Lycopersicum esculentum on apoptosis during NDEA induced hepatocarcinogenesis. Biochem Biophys Res Commun 2013;434:479-85.

19. Sarkar PD, Gupt T, Sahu A. Comparative analysis of lycopene in oxidative stress. J Assoc Physicians India 2012;60:17-9.

20. Martí R, Roselló S, Cebolla-Cornejo J. Tomato as a source of carotenoids and polyphenols targeted to cancer prevention. Cancers (Basel) 2016;8:E58.

21. Ge XX, Xing MY, Yu LF, Shen P. Carotenoid intake and esophageal cancer risk: a meta-analysis. Asian Pac J Cancer Prev 2013;14:1911-8

22. Gupta P, Bhatia N, Bansal MP, Koul A. Lycopene modulates cellular proliferation, glycolysis and hepatic ultrastructure during hepatocellular carcinoma. World J Hepatol 2016;8:1222-33.

23. Bhatia N, Gupta P, Singh B, Koul A. Lycopene enriched tomato extract inhibits hypoxia, angiogenesis, and metastatic markers in early stage N-nitrosodiethylamine induced hepatocellular carcinoma. Nutr Cancer 2015;67:1268-75.

24. Anthon G, Barrett DM. Standardization of a rapid spectrophotometric method for lycopene analysis. Acta Hortic 2007;758:111-28.

25. Cvetković D, Marković D. Stability of carotenoids toward UV-irradiation in hexane solution. J Serb Chem Soc 2008;73:15-27.

26. Dacie JV, Lewis SM. Practical Haematology. 7th edition. Edinburgh: Churchill Livingstone; 1991. p. 37-85.

27. Trush MA, Mimnaugh EG, Ginsburg E, Gram TE. In vitro stimulation by paraquat of reactive oxygen-mediated lipid peroxidation in rat lung microsomes. Toxicol Appl Pharmacol 1981;60:279-86.

28. Moron MS, Depierre JW, Mannervik B. Levels of glutathione, glutathione reductase and glutathione-s-transferase activities in rat lung and liver. Biochim Biophys Acta 1979;582:67-78.

29. Habig WH, Pabst MJ, Jakoby WB. Glutathione-S-transferases: the first enzymatic step in mercapturic acid formation. $J$ Biol Chem 1974;249:7130-9.

30. Paglia DE, Valentine WN. Studies on the quantitative and qualitative characterization of erythrocyte glutathione peroxidase. $J$ Lab Clin Med 1967;70:158-69.

31. Williams CH, Arscott LD. Glutathione reductase. Methods Enzymol 1971;17:503-9.

32. Luck H. Catalase. In: Methods in Enzymatic Analysis. New York: Academic Press; 1963. p. 885-98.

33. Kono Y. Generation of superoxide radical during auto-oxidation of hydroxylamine and assay for superoxide dismutase. Arch Biochem Biophys 1978;186:189-95.

34. Neyt S, Huisman MT, Vanhove C, De Man H, Vliegen M, Moerman L, Dumolyn C, Mannens G, De Vos F. In vivo visualization and quantification of (Disturbed) Oatp-mediated hepatic uptake and Mrp2-mediated biliary excretion of 99mTc-mebrofenin in mice. $J$ Nucl Med 2013;54:624-30.

35. Koul A, Mohan V, Bharati S. Azadirachta indica mitigates DMBA-induced hepatotoxicity: a biochemical and radiometric study. Indian J Biochem Biophys 2014;51:37-45.

36. Joseph B, Bhargava KK, Tronco GG, Kumaran V, Palestro CJ, Gupta S. Regulation of hepatobiliary transport activity and noninvasive identification of cytokine-dependent liver inflammation. J Nucl Med 2005;46:146-52.

37. Deshpande UR, Joseph LJ, Samuel AM. Hepatobiliary clearance of labelled mebrofenin in normal and D-galactosamine HCl-induced hepatitis rats and the protective effect of turmeric extract. Indian J Physiol Pharmacol 2003;47:332-6.

38. Leslie EM, Deeley RG, Cole SPC. Multidrug resistance proteins: role of P-glycoprotein, MRP1, MRP2, and BCRP (ABCG2) in tissue defense. Tox Appl Pharm 2005;204:216-37.

39. Olteanu D, Filip A, Mureşan A, Nagy A, Tabaran F, Moldovan R, Decea N, Catoi C, Clichici S. The effects of chitosan and low dose dexamethasone on extrahepatic cholestasis after bile duct ligation in Wistar rats. Acta Physiol Hung 2012;99:61-73.

40. Ghorbel I, Maktouf S, Kallel C, Ellouze Chaabouni S, Boudawara T, Zeghal N. Disruption of erythrocyte antioxidant defense system, hematological parameters, induction of pro-inflammatory cytokines and DNA damage in liver of co-exposed rats to aluminium and acrylamide. Chem Biol Interact 2015;236:31-40.

41. Farooq R, Bhat AA, Wani HA, Bashir H, Naikoo NA, Amin S. Role of hematological parameters in diagnosis and prognosis of gastric carcinoma in kashmir, india. Int Res J Pharm 2013;4:134-7.

42. Gangar SC, Sandhir R, Koul A. Effects of Azadirachta indica on certain hematological parameters during benzo(a)pyrene induced murine forestomach tumorigenesis. Eur Rev Med Pharmacol Sci 2010;14:1055-72.

43. Boeira SP, Filho CB, Del'Fabbro L, Roman SS, Royes LF, Fighera MR, Jessé CR, Oliveira MS, Furian AF. Lycopene treatment prevents hematological, reproductive and histopathological damage induced by acute zearalenone administration in male Swiss mice. Exp Toxicol Pathol 2014;66:179-85.

44. Ibrahim ATA. Protective role of lycopene and vitamin E against diazinon-induced biochemical changes in Oreochromis niloticus. Afr $J$ Environ Sci Technol 2015;9:557-65.

45. Afifi N, Ramadan A, Yassin NZ, Fayed HM, Abdel-Rahman RF. Molecular mechanisms underlying hepatoprotective effect of artichoke extract: modulates TNF-induced activation of nuclear transcription factor (NF-kappa B) and oxidative burst inhibition. World J Pharm Pharm Sci 2015;4:1546-62.

46. Abdel-Hamid NM, Nazmy MH, Abdel-Ghany MI, Nazmy WH. Cytokines as important playmakers of experimental hepatocarcinogenesis confounded by diabetes. Ann Hepatol 2012;11:118-27.

47. Riso P, Visioli F, Grande S, Guarnieri S, Gardana C. Effect of a tomato-based drink on markers of inflammation, immunomodulation, and oxidative stress. J Agr Food Chem 2006;54:2563-6.

48. Feng D, Ling WA, Duan RD. Lycopene suppresses LPS-induced NO and IL-6 production by inhibiting the activation of ERK, p38MAPK, and NF-jB in macrophages. Inflamm Res 2010;59:115-21. 
49. Oguz E, Kocarslan S, Tabur S, Sezen H, Yilmaz Z, Aksoy N. Effects of lycopene alone or combined with melatonin on methotrexateinduced nephrotoxicity in rats. Asian Pac J Cancer Prev 2015;16:6061-6.

50. Pracheta P, Sharma V, Paliwal R, Sharma S, Singh L, Janmeda BS, Savita, Yadav S, Sharma SH. Chemoprotective activity of hydroethanolic extract of Euphorbia neriifolia Linn leaves against DENA-induced liver carcinogenesis in mice. Biol Med 2011;3:36-44.

51. Traverso N, Ricciarelli R, Nitti M, Marengo B, Furfaro AL, Pronzato MA, Marinari UM, Domenicotti C. Role of glutathione in cancer progression and chemoresistance. Oxid Med Cell Longev 2013;2013:972913.

52. Dogukan A, Tuzcu M, Agca CA, Gencoglu H, Sahin N,Onderci M, Ozercan IH, Ilhan N, Kucuk O, Sahin K. A tomato lycopene complex protects the kidney from cisplatin-induced injury via affecting oxidative stress as well as Bax, Bcl-2, and HSPs expression. Nutr Cancer 2011;63:427-34.

53. Vijayakumar D, Suresh K, Manoharan S. Lipid peroxidation and antioxidant status in blood of rheumatoid arthritis patients. Indian $J$ Clin Biochem 2006;21:104-8.

54. Huang Z, Chen C, Zeng Z, Yang H, Oh J, Chen L, Lu SC. Mechanism and significance of increased glutathione level in human hepatocellular carcinoma and liver regeneration. FASEB J 2001;15:19-21.

55. Maffei F, Angeloni C, Malaguti M, Moraga JM, Pasqui F, Poli C, Colecchia A, Festi D, Hrelia P, Hrelia S. Plasma antioxidant enzymes and clastogenic factors as possible biomarkers of colorectal cancer risk. Mutat Res 2011;714:88-92.

56. Ural MS. Chlorpyrifos-induced changes in oxidant/antioxidant status and haematological parameters of Cyprinus carpio: ameliorative effect of lycopene. Chemosphere 2013;90:2059-64.

57. Sadik NAH, EL-Maraghy SA, Ismail MF. Diethylnitrosamine-induced hepatocarcinogenesis in rats: possible chemoprevention by blueberries. Afr J Biochem Res 2008;2:81-7.

58. Li T, Zhao XP, Wang LY, Gao S, Zhao J, Fan YC, Wang K. Glutathione S-transferase P1 correlated with oxidative stress in hepatocellular carcinoma. Int J Med Sci 2013;10:683-90.

59. Shaker E, Mahmoud H, Mnaa S. Silymarin, the antioxidant component and Silybum marianum extracts prevent liver damage. Food Chem Toxicol 2010;48:803-6. 